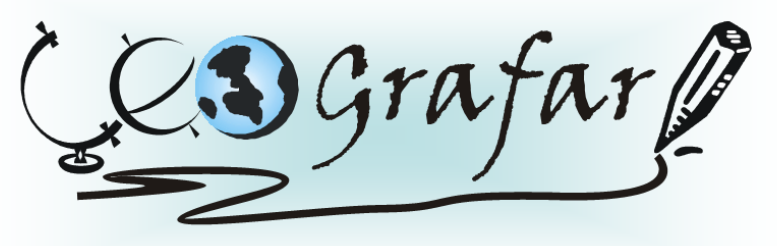

Revista Eletrônica do Programa de Pós-Graduação em Geografia - UFPR

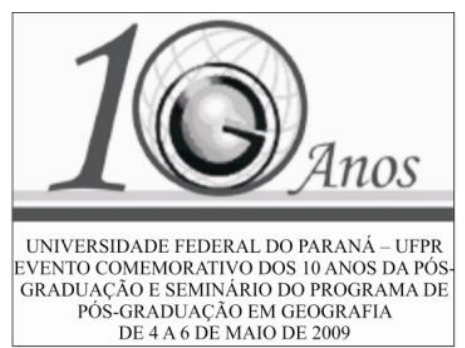

\title{
A RESSIGNIFICAÇÃO DA PAISAGEM LITORÂNEA DO PARANÁ: IMAGENS DE UM PASSADO PRESENTE NAS MEMÓRIAS DAS COMUNIDADES CAIÇARAS DE GUARAQUEÇABA - PR
}

\author{
HELENA MIDORI KASHIWAGI ${ }^{1}$ \\ SALETE KOZEL ${ }^{2}$ \\ TERRITÓRIO, CULTURA E REPRESENTAÇÃO
}

Essa pesquisa tem como objetivo analisar a ressignificação da paisagem do litoral paranaense, compreendendo as imagens de um passado presente nas memórias das comunidades caiçaras de Guaraqueçaba, inseridas na baia de Pinheiros, com um olhar especial para a comunidade de Barbados. Esta comunidade é uma das mais antigas da região e os primeiros habitantes surgiram por volta de 1700, constituindo-se, assim, de relevante importância cultural e histórica para a compreensão e re-interpretação das imagens da paisagem atual. As políticas públicas ambientais, na busca de preservar e proteger a Mata Atlântica regulamentou severas leis ambientais, nas quais as comunidades não foram contempladas plenamente no âmbito da Lei. As práticas seculares de sobrevivência como a pesca, a caça de subsistência, a agricultura e o extrativismo vegetal e de mangue foram proibidos com a criação das unidades de conservação. Desta forma, percebe-se na região um processo lento e resistente de abandono do lugar e gradativa aculturação, além da substituição dos meios de sobrevivência e adaptação às novas regras. Nesta tentativa de sobrevivência, o ecoturismo tem sido uma das novas atividades que tem possibilitado alguma geração de renda, porém, devido a sazonalidade do turismo na região, esta fonte de renda tem sido insuficiente para a sobrevivência das famílias e a prática de atividades ilegais são recorrentes e inevitáveis. O policiamento ambiental por terra e por mar visa capturar os infratores da Lei na região, provocando sentimento de medo, revolta e um alto índice de depressão entre os moradores locais. Essas práticas ilegais de sobrevivência são um dos principais motivos dos

\footnotetext{
${ }^{1}$ helenamidori@ufpr.br

${ }^{2}$ Professora orientadora
} 
conflitos socioambientais entre as comunidades caiçaras e o poder público. A não compreensão do conhecimento empírico, da herança cultural e da tradição dos saberes populares, do respeito pela natureza e do uso de forma sustentável dos recursos naturais tem demonstrado a prepotência do saber científico sobre o saber local. As Leis ambientais regulamentam novos territórios, construindo barreiras invisíveis no meio natural, que transpõem as territorialidades dos grupos humanos presentes. A relação culturalmente vivida com a trama de lugares hierarquizados e interdependentes do sistema espacial é modificada, o espaço-território é transformado. A territorialidade é compreendida muito mais pela relação social e cultural que um grupo mantém com a trama de lugares e itinerários que constituem seu território do que pela referência aos conceitos habituais de apropriação biológica e de fronteira. (Bonnemaison, 2002) Para tal compreensão é essencial perceber as diferenças sobre o espaço e o território, entendendo que o espaço é anterior ao território, pois o território se forma a partir do espaço, é o resultado de uma ação conduzida por um ator sintagmático (ator que realiza um programa) em qualquer nível. Ao se apropriar de um espaço, concreta ou abstratamente (por exemplo, pela representação), o ator 'territorializa' o espaço. Segundo Raffestin (1993, p. 143) o mecanismo de passar de espaço ao território é bem definido por Lefèbvre ao discorrer sobre a produção de um espaço como, por exemplo, o território nacional, um espaço físico, que é constantemente modificado, transformado pelas redes, circuitos e fluxos que nele se instalam, tais como, rodovias, canais, estradas de ferro, circuitos comerciais e bancários, auto-estradas, rotas aéreas entre outros. (Lefèbvre, 1978 apud Raffestin, 1993, p. 143) O autor ressalta que o território nesta perspectiva “... é um espaço onde se projetou um trabalho, seja energia e informação, e que, por conseqüência, revela relações marcadas pelo poder. O espaço é a 'prisão original', o território é a prisão que os homens constroem para si”. O território se apóia no espaço, mas não é o espaço, é uma produção a partir do espaço. Essas relações marcadas pelo poder se fortaleceram com a representação da imagem, construída a partir de uma realidade, que subsidiou a evolução da cartografia, tornando-a um instrumento de poder e do "Poder". As imagens ou as representações do espaço resultam da combinação dos elementos: superfície ou plano, da linha ou reta e do ponto. Essa representação permitiu delimitar territórios, o traçado das rodovias, cidades, ilhas, fazer coincidir uma fronteira com uma linha de cristas ou um rio, preservar o acesso às rodovias e alguns casos a vontade de atingir o mar. Contudo, essas representações também podem ser feitas de maneira intuitiva, onde um ator como elemento do sistema, produz uma representação egocêntrica, pois é uma manifestação do "eu" ao "não 
eu", uma explicitação da interioridade em relação à exterioridade. É a representação do espaço do ator, evidentemente, que esta não esgota todo o conteúdo presente neste espaço, pois se trata da transcrição dos objetivos intencionais. Essa representação não se refere ao "espaço", mas de um espaço construído pelo ator, portanto, o espaço representado não é mais o espaço, mas a imagem do espaço, ou melhor, do território visto e/ou vivido. "É, em suma, o espaço que se tornou o território de um ator, desde que tomado numa relação social de comunicação.” (RAFFESTIN, 1993, p. 144-147) O espaço só existe em função dos objetivos intencionais do ator, onde o espaço é um lugar ou um campo de possibilidades, no qual o ator pode decidir construir vários tipos de tessituras e articular todos os pontos, ou somente alguns, em redes. Conforme os objetivos intencionais são possíveis criar diversas imagens territoriais. Logicamente, existem diferenças entre a imagem territorial projetada e o território real, pois uma imagem nunca é transcrita tal e qual ela é representada no plano. Na representação da imagem territorial projetada, o ator faz a repartição da superfície, a implantação dos nós e redes a partir dos seus objetivos intencionais, representando o que Raffestin denomina de "essencial visível" sobre o espaço. As imagens territoriais revelam as relações de produção e consequentemente às relações de poder, e é decifrando-as que compreendemos a estrutura do território. A construção do território se dá do Estado ao indivíduo, por exemplo, o Estado organiza o território nacional por intermédio de novos recortes, de novas implantações, o mesmo ocorre com empresas ou organizações, também para o indivíduo que reorganiza sua casa ou apartamento. Enfim, diversos níveis, momentos diferentes e lugares variados, somos todos atores que produzem "territórios". (RAFFESTIN, 1993, p. 148-150) Nesta discussão, Raffestin (1993, p. 153-155) ressalta que falar de território é fazer uma referência implícita à noção de limite que, mesmo não sendo traçado, como em geral ocorre, exprime a relação que um grupo mantém com uma porção do espaço. Isto é, a ação deste grupo gera, de imediato, a delimitação. $\mathrm{O}$ autor ressalta ainda que “... delimitar é, pois, isolar ou subtrair momentaneamente ou, ainda, manifestar um poder numa área precisa. O desenho de uma malha ou de um conjunto de malhas é a consequiência de uma relação com o espaço e, por conseguinte, a forma mais elementar da produção do território". Esta malha constitui o tecido territorial que é sempre um enquadramento do poder ou de um poder e sua respectiva escala é que determina a escala de poderes, exprimindo a área de exercício dos poderes ou a área de capacidade dos poderes. Raffestin considera que os limites não são somente do ponto de vista linear, mas também do ponto de vista zonal, contrariando a percepção comumente apreendida sobre os limites que conduzem a privilegiar a linha em detrimento da zona, hábito este 
condicionado sobre a experiência primária que se tem sobre fronteira, contribuindo para essa maneira de ver. A malha territorial não é homogênea e nem uniforme, pois acolhe além da população, outros elementos que revelam a organização territorial, ou seja, os pontos ou as nodosidades territoriais e os marcos. Para Raffestin (193, p. 158) a territorialidade reflete a muldimensionalidade do "vivido" territorial, onde os homens vivem o processo territorial e o produto territorial por intermédio de um sistema de relações existenciais e/ou produtivistas, as quais interagem com os atores numa relação de poder e que procuram modificar as relações com a natureza e com as relações sociais. Os atores, sem perceberem se automodificam também. Todas as relações são de alguma forma marcada pelo poder. Segundo o autor, a noção de territorialidade é muito clara no mundo animal, mas a territorialidade humana, ainda, tem sido objeto de pesquisa e investigação. Essa noção foi verdadeiramente explicada pelos naturalistas em 1920, por H. E. Howard, que a definiu como “... a conduta característica adotada por um organismo para tomar posse de um território e defendê-lo contra os membros de sua própria espécie". Posteriormente, outros autores também desenvolveram essa idéia de territorialidade animal, tais como, John B. Calhoun, Karl Von Frisch, H. Hediger e Konrad Lorenz. Na mesma perspectiva de Bonnemaison (2002, p. 99) afirma que nas sociedades animais o território está ligado à idéia de apropriação biológica, ou seja, ele é exclusivo para os membros de uma mesma espécie, e é limitado por uma fronteira. Assim, descreve que na periferia do território, a fronteira aparece como um espaço perigoso, uma zona de competição, na qual o animal sozinho ou em grupo, se arrisca e desafia outro animal do grupo vizinho. Ele não penetra no território vizinho. Diante deste exemplo, percebe-se na área de estudo conflitos territoriais entre as comunidades caiçaras e o policiamento ambiental. Nesta perspectiva, busca-se com a abordagem sociocultural, identificar e decodificar as construções sígnicas que constituem diferentes territorialidades, paisagens e representações. A investigação utilizará como ferramenta de diagnóstico os mapas mentais. Os aportes teóricos e metodológicos para interpretação dos signos se fundamentam nas teorias lingüísticas de Bakhtin e na hermenêutica associados a metodologia Kozel (2001) para interpretação das imagens mentais. Busca-se identificar nas imagens do passado, ainda, vividas nas memórias das pessoas, os elementos que representam a verdadeira identidade e essência do lugar.

Palavras-chave: Paisagem, Território, Mapas Mentais. 